\title{
BEBAN EMISI AKTIVITAS LTO PESAWAT UDARA DI BANDAR UDARA INTERNASIONAL I GUSTI NGURAH RAI BALI
}

\author{
Yohanis Umbu Kaleka ${ }^{1 *}$,I Wayan Budiarsa Suyasa ${ }^{1}$, Made Sudiana Mahendra ${ }^{1}$ \\ ${ }^{1}$ Program Studi Magister Ilmu Lingkungan Universitas Udayana Bali \\ "Email : yohanumbu07@gmail.com
}

\begin{abstract}
I Gusti Ngurah Rai Bali International Airport is the second highest airport in activity level in Indonesia. Flight activity in this airport increases every year, with an increase of $20 \%$ from 2011 until the end of 2012. The research aimed to identify how much the LTO (Landing-Take-Off) emission activity in I Gusti Ngurah Rai Bali International Airport. The purpose of this research was to identify how much the emission is and the effect of LTO activities towards the ambient air condition of $\mathrm{CO}$ and $\mathrm{NO}_{\mathrm{x}}$ around the airport. Three measurement points and three days recent flight were applied to understand the emission spreading characteristic in every LTO phases. The three phases of LTO which are consisted of take-off phase, taxi in phase and landing phase, were the main focus of this research. The three recent flights were on Monday 5 of May, on Wednesday 7 of May and on Saturday 10 of May in 2014. Regression bifilar linear statistical analysis method was employed to identify the effect and how big the $\mathrm{CO}$ and $\mathrm{NO}_{\mathrm{x}}$ emission contribution towards the ambient air quality.

The results of this research showed that the emission of aircraft activity in LTO phases was effected by the ambient air concentration of $\mathrm{CO}$ and $\mathrm{NO}_{\mathrm{x}}$. It was proved with the result from $\mathrm{F}$ test simultaneous with significant level average $0,033<0,005$ and with $r$ value that exists between $0,77-0,97$ with mean contribution was $79,1 \%$. Take-off phase was the phase that produced the biggest $\mathrm{NO}_{\mathrm{x}}$ gas emission compared to the other phases. When the aircraft did the take-off phase, the thrust was used reached $100 \%$, the purpose was to produce the big energy. The combustion that happened in take-off phase in aircraft machine classified in perfect combustion, also this thing effected the phase to produce the smallest CO gas emission compared with the other phases. Taxi in phase was a phase that produced the biggest $\mathrm{CO}$ emission between the two other phases, it was happened because the thrust needed just $7 \%$ only so the combustion in aircraft machine classified in imperfect combustion and it was effected the $\mathrm{CO}$ emission was increasingly while the landing phase was the phase that produced the smallest $\mathrm{CO}$ and $\mathrm{NO}_{\mathrm{x}}$ gas emission compared to the other phases. Measurement results of the $\mathrm{CO}$ and $\mathrm{NO}_{\mathrm{x}}$ concentration in every point in three days recent flight was still under the quality standard that has been settled appropriate in Government Act number 41 year 1999.
\end{abstract}

Keywords: Aircraft Emission; Landing-Take-Off; $\mathrm{NO}_{\mathrm{x}}$ and CO; I GustiNgurahRai Bali InternationallAirport1.

\section{PENDAHULUAN}

Bandar Udara Internasional I Gusti Ngurah Rai Bali merupakan Bandar Udara yang mempunyai tingkat kesibukan nomor dua di Indonesia setelah Bandar Udara Internasional Sukarno Hatta di Jakarta dan merupakan pintu gerbang lalu lintas angkutan udara dari sisi sebelah timur Indonesia dengan luas area 283,72 Ha. Data statistik menyatakan bahwa aktivitas penerbangan yang berlangsung di bandara ini mengalami peningkatan jumlah dari tahun ke tahun. Hal ini terlihat dari jumlah pada tahun 2011 sebanyak 49.509 kali penerbangan meningkat menjadi 58.874 kali penerbangan atau mengalami peningkatan sebanyak 20\% pada akhir tahun 2012 (PT. Angkasa Pura, 2012).

Dokumen Aviation and Emission - A Prime (2005) yang dikeluarkan FAA menyatakan bahwa mesin pesawat menghasilkan emisi yang sama seperti mesin kendaraan bermotor, yaitu karbon dioksida $\left(\mathrm{CO}_{2}\right)$, uap air $\left(\mathrm{H}_{2} \mathrm{O}\right)$, nitrogen oksida $\left(\mathrm{NO}_{\mathrm{x}}\right)$, karbon monoksida (CO), dan sulfur oksida $\left(\mathrm{SO}_{\mathrm{x}}\right)$. Aktivitas penerbangan yang dilakukan oleh sebuah pesawat terbang terdiri atas dua fase yaitu fase Landing-Take-Off (LTO) dan fase cruise (fase jelajah). Fase LTO adalah fase dimana aktivitas pesawat udara di bawah ketinggian 914 meter dari permukaan tanah sedangkan fase cruise adalah fase yang dilalui pesawat udara di atas ketinggian 914 meter. Penelitian ini difokuskan pada aktivitas pesawat udara pada fase LTO karena hal ini sangat terkait terhadap kualitas udara lokal di Bandar Udara dan daerah sekitarnya.

Penelitian ini dilakukan untuk mendapatkan hubungan antara emisi $\mathrm{CO}$ dan $\mathrm{NO}_{\mathrm{x}}$ pada fase Landing-Take-Off yang diakibatkan oleh adanya aktivitas pesawat udara baik berupa kedatangan maupun keberangkatan di Bandar Udara I Gusti Ngurah Rai Bali terhadap konsentrasi $\mathrm{CO}$ dan $\mathrm{NO}_{x}$ yang diukur secara in-situ. Berdasarkan data yang dikeluarkan oleh EMEP tahun 2009, pengukuran emisi pesawat udara pada fase LTO yang lebih akurat dapat dibagi dalam beberapa fase-fase kecil 
diantaranya fase Taxi out, Take Off, Climb Out, Approach Landing, Landing dan Taxi in. Untuk kepentingan pengukuran pada ketujuh fase tersebut, sampai saat ini EMEP baru mengeluarkan besar konsumsi bahan bakar dan faktor emisi untuk gas $\mathrm{CO}, \mathrm{NO}_{\mathrm{x}}$, dan $\mathrm{HC}$ sedangkan beberapa gas pencemar lainnya belum tersedia. Pengukuran HC secara insitu secara akurat sampai saat ini masih mengalami kesulitan karena secara kimiawi HC sangat cepat mengalami proses oksidasi, sehingga penelitian ini hanya difokuskan pada $\mathrm{CO}$ dan $\mathrm{NO}_{\mathrm{x}}$. Hasil dari penelitian ini dapat digunakan sebagai salah satu faktor evaluasi kinerja Bandar Udara terkait dengan lingkungan, khususnya kualitas udara di area sekitar Bandar Udara.

\section{METODE}

\subsection{Lokasi dan Waktu Penelitian}

Penelitian ini dilaksanakan di Bandar Udara Internasional I Gusti Ngurah Rai Bali dengan mengambil sampel tiga hari yang mewakili aktivitas penerbangan dalam satu minggu yaitu awal minggu, pertengahan minggu dan akhir minggu masingmasing pada hari Senin 5 Mei, Rabu tanggal 7 Mei dan hari Sabtu tanggal 10 Mei 2014.

\subsection{Penentuan Sumber Data}

Sumber data yang digunakan dalam penelitian ini dibagi atas dua, yaitu data primer dan data sekunder.

\subsection{Penentuan Koordinat Pengambilan Sampel}

Titik sampel pengukuran kualitas udara ambien dilakukan di beberapa titik. Pengambilan sampel dalam penelitian ini mewakili fase Landing, Taxi in, dan Take Off.Ketiga titik tersebut dapat dilihat pada Gambar 1.

\subsection{Instrumen Penelitian}

Instrumen yang digunakan adalah rangkaian alat impinger, terdiri dari sebuah rol kabel, sebuah pompa vakum, empat buah tabung impinger yang dilengkapi dengan kaca pasir, dan rak tabung.

\subsection{Prosedur Penelitian}

\subsubsection{Pengambilan Data Primer}

Pengambilan sampel $\mathrm{CO}$ dan $\mathrm{NO}_{\mathrm{x}}$ udara ambien dilakukan pada 3 titik lokasi pengukuran yang mewakili setiap fase LTO. Pengambilan sampel $\mathrm{NO}_{\mathrm{x}}$ dan CO dilakukan mulai pukul 08.00 WITA sampai pukul 23.00 WITA. Pengambilan data primer

Tabel 1. Jadwal Pengambilan Sampel $\mathrm{CO}$ dan $\mathrm{NO}_{x}$ dalam Satu Hari

\begin{tabular}{cccc}
\hline Pukul & Titik I & Titik II & Titik III \\
\hline Pukul (WITA) & 10.00 & 09.00 & 08.00 \\
& 13.00 & 12.00 & 11.00 \\
& 16.00 & 15.00 & 14.00 \\
& 19.00 & 18.00 & 17.00 \\
& 22.00 & 21.00 & 20.00 \\
\hline
\end{tabular}

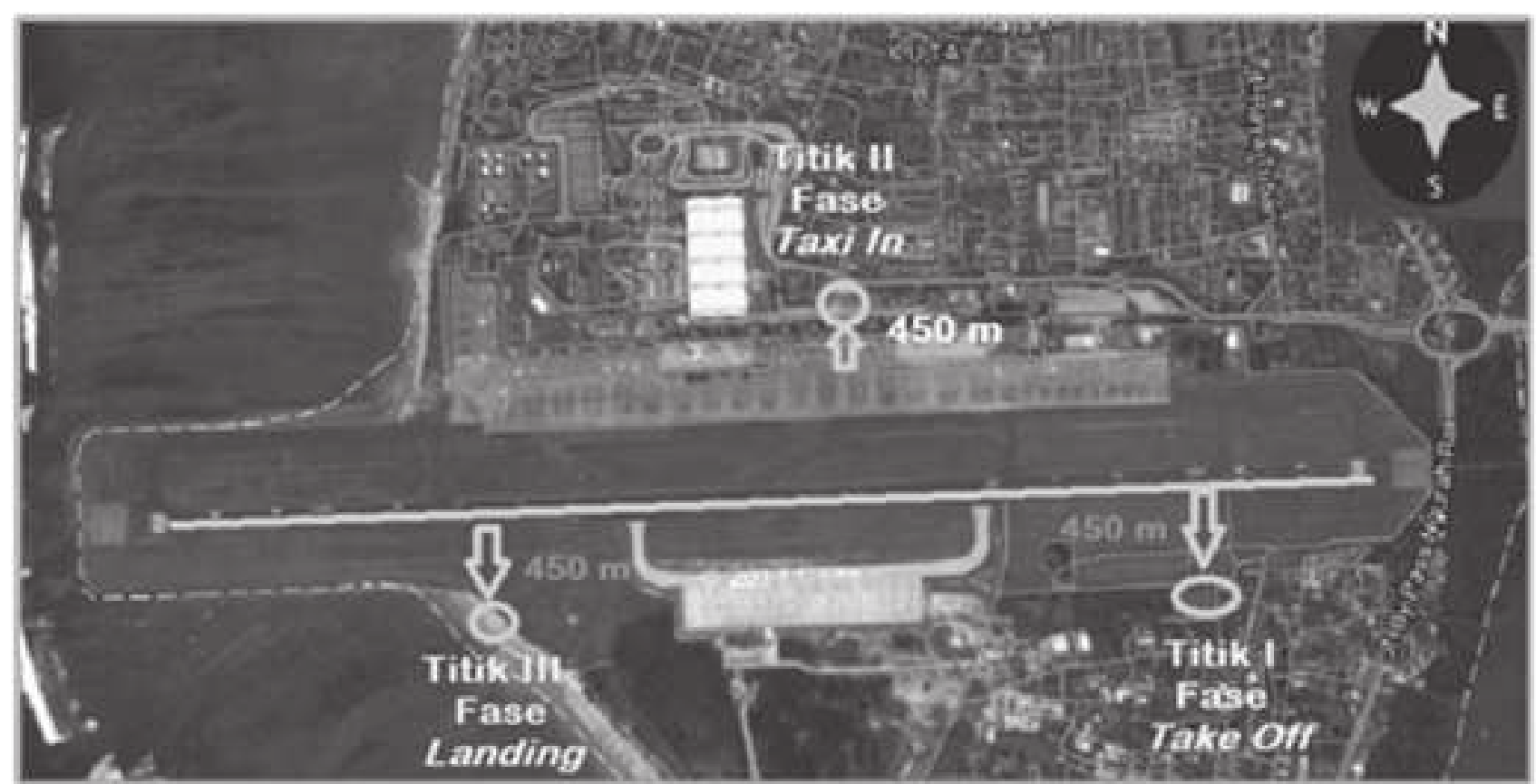

Gambar 1. Letak Pengambilan Sampel

Keterangan

1. Titik 1, titik pengambilan sampel fase Take Off( $450 \mathrm{~m})$ dengan koordinat $08^{\circ} 45^{\prime} 02^{\prime \prime} \mathrm{LS}$ dan $115^{\circ} 10^{\prime} 37^{\prime \prime} \mathrm{BT}$

2. Titik 2, titik pengambilan sampel fase Taxi In ( $450 \mathrm{~m}$ ) dengan koordinat $08^{\circ} 44^{\prime} 42^{\prime \prime}$ LS dan $115^{\circ} 10^{\prime} 14^{\prime \prime}$ BT

3. Titik 3 , titik pengambilan sampel fase Landing $\left(450 \mathrm{~m}\right.$ ) dengan koordinat $08^{\circ} 45^{\prime} 07^{\prime \prime} \mathrm{LS}$ dan $115^{\circ} 09^{\prime} 47^{\prime \prime} \mathrm{BT}$ 
dilakukan pada hari Senin, Rabu dan Sabtu. Pengambilan sampel pada ke tiga titik dalam satu hari ditunjukkan pada Tabel 1 dan pada tren hari berikutnya dilakukan hal yang sama.

\subsubsection{Pengambilan Data Sekunder}

Pengumpulan data sekunder dilakukan dalam periode waktu yang sama dengan pengambilan data primer. Data sekunder diperoleh dari Airnav Indonesia Cabang Denpasar. Data yang dikumpulkan adalah data jumlah LTO dan tipe pesawat baik penerbangan domestik maupun penerbangan internasional. Data sekunder lainnya adalah faktor emisi yang ditetapkan oleh EMEP dalam dokumen CORINAIR. Perhitungan emisi menggunakan persamaan dengan pendekatan Tier-2 dalam dokumen CORINAIR GB 2009 1.A.3.a, 1.A.5.b Aviation.

\subsection{Analisis Data}

Tahap analisis data dilakukan dalam tiga tahap yaitu pengolahan data $\mathrm{CO}$ dan $\mathrm{NO}_{\mathrm{x}}$ udara ambien, perhitungan beban emisi fase LTO dan melakukan analisisi statistik dengan metode regresi linear berganda untuk menentukan pengaruh dan kontribusi emisi terhadap konsentrasi hasil pengolahan data $\mathrm{CO}$ dan $\mathrm{NO}_{\mathrm{x}}$ udara ambien.

\section{HASIL DAN PEMBAHASAN}

\subsection{Perhitungan Beban Emisi CO dan $\mathrm{NO}_{\mathrm{x}}$ Pesawat Udara pada Awal, Pertengahan dan Akhir Minggu}

Perhitungan beban emisi CO dan $\mathrm{NO}_{\mathrm{x}}$ pesawat udara fase LTO dalam tiga tren hari penerbangan menggunakan data aktivitas pesawat dari pukul 05.00 WITA sampai pukul 23.00 WITA. Emisi kedua gas tersebut dihasilkan pada fase take off, taxi in dan landing. Total emisi gas $\mathrm{NO}_{\mathrm{x}}$ dan $\mathrm{CO}$ pada masing-masing tren hari penerbangan disajikan pada Tabel 2.

Tabel 2. Perbandingan $\mathrm{Emisi}_{\mathrm{NO}}$ dan $\mathrm{CO}$ per Tren Hari Penerbagan

\begin{tabular}{cccc}
\hline $\begin{array}{c}\text { Tren Hari } \\
\text { Penerbangan }\end{array}$ & Jml Aktivitas & $\mathrm{NO}_{\mathbf{x}}$ (kg/hari) & $\mathbf{C O}$ (kg/hari) \\
\hline Awal Minggu & 205 & $34.385,23$ & $16.750,33$ \\
Pertengahan Minggu & 297 & $73.485,52$ & $40.515,17$ \\
Akhir Minggu & 184 & $40.853,28$ & $27.133,05$ \\
$\quad$ Total & 686 & $148.724,00$ & $84.398,55$ \\
\hline
\end{tabular}

Keterangan:

Awal Minggu : Senin 5 Mei 2014

Pertengahan Minggu : Rabu 7 Mei 2014

Akhir Minggu : : Sabtu 10 Mei 2014

Berdasarkan Tabel 2, aktivitas penerbangan dalam tiga tren penerbangan tertinggi terjadi pada penerbangan pertengahan minggu sebanyak $297 \mathrm{kali}$ aktivitas yang diikuti dengan emisi gas $\mathrm{NO}_{\mathrm{x}}$ dan $\mathrm{CO}$ yang besar pula dari dua tren hari lainnya.

Berdasarkan hasil perhitungan pada masingmasing hari tren penerbangan pada ketiga fase penerbangan LTO, fase take off adalah fase yang menghasilkan emisi gas $\mathrm{NO}_{\mathrm{x}}$ yang terbesar di antara fase lainnya. Hasil perhitungan rata-rata emisi gas $\mathrm{NO}_{\mathrm{x}}$ fase take off dalam tiga tren hari penerbangan tersebut adalah $38.910,81 \mathrm{~kg} / \mathrm{hari}$. Besarnya emisi $\mathrm{NO}_{\mathrm{x}}$ pada fase take off terjadi karena pada fase ini, thrust yang digunakan pesawat udara mencapai 100\% (ICAO, 2010). Besaran thrust ini digunakan untuk menghasilkan energi yang digunakan untuk menanjak ke atas. Untuk menghasilkan energi yang besar, maka bahan bakar yang diperlukan juga harus besar, hal ini terbukti dari data faktor emisi yang ditetapkan oleh EMEP dimana fase take off adalah fase yang menggunakan bahan bakar terbesar dibandingkan dengan fase lainnya. Besar daya dan bahan bakar yang digunakan akan berimbas pada beban emisi gas $\mathrm{NO}_{\mathrm{x}}$ yang besar pula. Untuk menghasilkan daya atau energi yang cukup, maka pembakaran yang terjadi dalam mesin pesawat harus sempurna. Pembakaran sempurnah akan terjadi apabila terdapat oksigen yang cukup dalam mesin pesawat. Hal ini juga yang menyebabkan fase ini menghasilkan emisi gas $\mathrm{CO}$ yang jauh lebih kecil dari gas $\mathrm{NO}_{\mathrm{x}}$. Hasil perhitungan rata-rata emisi gas $\mathrm{CO}$ dalam tiga hari tren penerbangan tersebut adalah sebanyak $226,93 \mathrm{~kg} / \mathrm{h}$ ari jauh lebih kecil dari emisi $\mathrm{NO}_{\mathrm{x}}$.

Fase taxi in merupakan fase yang menghasilkan emisi gas $\mathrm{CO}$ terbesar diantara dua fase lainnya. Fase taxi in adalah fase dimana pesawat udara sudah melewati fase landing dan bergerak secara perlahan menuju ke lokasi appron (parkir). Karbon monoksida (CO) adalah gas yang tidak berwarna, tidak berbau, mudahterbakar dan sangat beracun. Merupakan hasil utama pembakaran karbo monoksidadan senyawa yang mengandung karbon monoksida yang tidak lengkap (Muryanto dkk, 2009). Karbon dan Oksigen dapat bergabung membentuk senyawa karbon monoksida (CO) sebagai hasil pembakaran yang tidak sempurna dan karbon dioksida $\left(\mathrm{CO}_{2}\right)$ sebagai hasil pembakaran sempurna (Fardiaz, 1992). Seperti pada kendaraan bermotor pada keadaan mendekati fase idle dan pada fase idle, maka di dalam mesin berlangsungreaksi pembakaran tidak sempurna akan timbul emisi gasbuang berupa gas karbon monoksida (Mukono, 2006).Rata-rata emisi gas CO per hari dalam tiga tren hari penerbangan adalah sebanyak $21.746,86 \mathrm{~kg} / \mathrm{hari}$. Emisi gas CO fase taxi in merupakan yang tertinggi dari fase lainnya karena daya yang digunakan hanya mencapai 7\% (ICAO,2010). Besaran thrus ini menunjukkan besarnya daya yang dibutuhkan untuk melakukan fase taxi in. Dengan thrust yang kecil ini, maka energi yang dibutuhkan sangat kecil. 
Fase landing adalah fase yang menghasilkan emisi gas $\mathrm{CO}$ dan $\mathrm{NO}_{\mathrm{x}}$ yang relatif rendah dari fase lainnya dan membutuhkan thrust sebesar 30\% (ICAO, 2010). Rata-rata emisi gas NO fase landingper tren hari penerbangan adalah $1.289,11 \mathrm{~kg} / \mathrm{hari}$, sedangkan rata-rata CO sebesar 481,40 kg/hari. Besaran thrust yang besar ini tidak linear dengan emisi yang dihasilkan dan lebih kecil dari fase lainnya, fenomena ini terjadi karena fase landing hanya memerlukan waktu yang lebih kecil dari fase taxi in yaitu hanya 4 menit. Waktu yang lebih sedikit akan meneyebabkan pembakaran tidak akan berlangsung lama, sehingga emisi yang dihasilkan juga akan lebih kecil.Berdasarkan data dari EMEP, konsumsi bahan bakar fase landing lebih kecil dari dua fase lainnya.

\subsection{Hasil Pengukuran CO dan $\mathrm{NO}_{x}$ Udara Ambien}

Konsentrasi hasil pengukuran $\mathrm{NO}_{\mathrm{x}}$ dan $\mathrm{CO}$ udara ambien secara umum masih berada di bawah baku mutu kualitas udara ambien sesuai dengan PP NO 41 tahun 1999. Untuk konsentrasi gas CO udara ambien. rata-rata konsentrasi CO udara ambien dalam tiga tren hari penerbangan pada masingmasing titik berada pada kisaran $781,01 \mu \mathrm{g} / \mathrm{Nm}^{3}-$ $842,41 \mu \mathrm{g} / \mathrm{Nm}^{3}$. Menurut Siswanto (1991) konsentrasi CO tersebut berada dalam kategori sedang (500$\left.1500 \mu \mathrm{g} / \mathrm{Nm}^{3}\right)$. Sedangkan untuk konsentrasi NO berada pada kisaran $82,23 \mu \mathrm{g} / \mathrm{Nm}^{3}-158,15 \mu \mathrm{g} / \mathrm{Nm}^{3}$.

\subsection{Analisis Hubungan Beban Emisi terhadap Konsentrasi NO dan CO Udara Ambien}

Analisis yang digunakan untuk mengetahui kuat hubungan dan besar kontribusi emisi setiap fase LTO terhadap hasil pengukuran $\mathrm{NO}_{\mathrm{x}}$ dan $\mathrm{CO}$ udara ambien adalah analisis statistik regresi linear berganda.

\subsubsection{Fase Take off Titik I (koefisien $b_{1}$ )}

Hasil analisis statistik regresi berganda yang diperloleh untuk parameter $\mathrm{NO}_{\mathrm{x}}$ rata-rata nilai $\mathrm{r}$ yang didapatkan pada tiga tren hari penerbangan adalah 0,90 menunjukkan korelasi yang kuat dengan ratarata tingkat kontribusi sebesar $82,83 \%$.Rata-rata nilai tingkat signifikan yang didapatkan pada tiga tren hari penerbangan adalah 0,036. Dari analisis uji t menunjukkan bahwa terdapat pengaruh parsial antara ketiga variabel fase LTO terhadap variabel konsentrasi $\mathrm{NO}$ dan $\mathrm{NO}_{2}$ yang terukur, dimana hanya terbukti pada variabeltake off (koefisien $b_{1}$ ) dengan tingkat signifikan untuk NO sebesar 0,030 dan untuk $\mathrm{NO}_{2}$ sebesar $0,034(\mathrm{p}<0,05)$. Hal ini menunjukkan bahwa beban emisi aktivitas take off berpengaruh nyata terhadap hasil pengukuran konsentrasi $\mathrm{NO}_{\mathrm{x}}$ udara ambien. Adanya pengaruh emisi gas $\mathrm{NO}_{\mathrm{x}}$ ini terhadap konsentrasi $\mathrm{NO}_{\mathrm{x}}$ udara ambien disebabkan oleh beberapa hal. Berdasarkan hasil perhitungan emisi parameter $\mathrm{NO}_{\mathrm{x}}$ fase take off, emisi $\mathrm{NO}_{\mathrm{x}}$ adalah yang terbesar dari fase lainnya karena thrust yang digunakan mencapai 100\%. Gambar 2 memperlihatkan kecepatan lontaran massa udara yang keluar dari hasil pembakaran dalam mesin pesawat. Kecepatan lontaran massa udara yang mengandung gas $\mathrm{NO}_{\mathrm{x}}$ dan $\mathrm{CO}$ mencapai 161 $\mathrm{km} / \mathrm{jam}$. Hasil perhitungan menunjukkan bahwa emisi gas $\mathrm{NO}_{\mathrm{x}}$ jauh lebih besar dari $\mathrm{CO}$, sehingga meskipun emisi gas $\mathrm{NO}_{\mathrm{x}}$ ini terlontar dengan kecepatan yang tinggi ke arah belakang masih ditemukan adanya pengaruh terhadap hasil pengukuran $\mathrm{NO}_{\mathrm{x}}$ udara ambien.

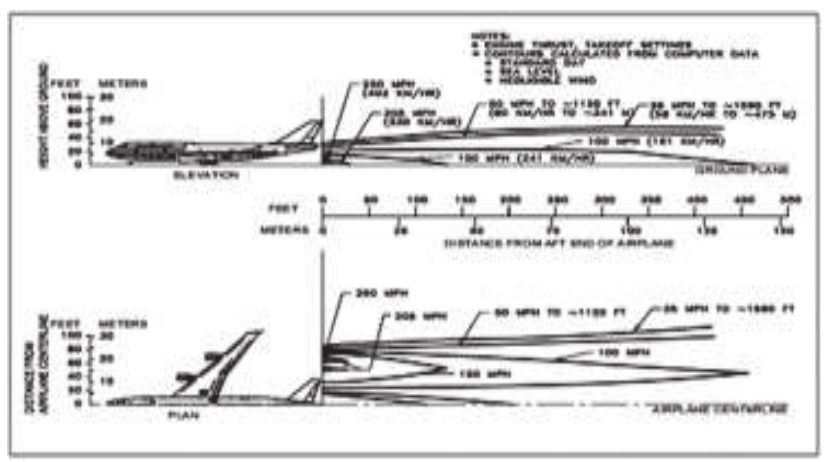

Gambar 2.Boeing 747 Exhaust Velocity Fase Take Off. Sumber: 747 Airport Planning Document (2002)

Kecepatan angin, arah angin, suhu dan kelembaban juga mempengaruhi hasil pengukuran $\mathrm{NO}_{\mathrm{x}}$ udara ambien. Berdasarkan data dari Stasiun BMKG Ngurah Rai Kelas I, Senin 5, 7 dan 10 Mei 2014 menyatakan bahwa angin bergerak menuju ke arah Timur atau dari landasan runway 29 dan bertiup ke arah runway 09 dengan rata-rata kecepatan $6 \mathrm{~m} / \mathrm{s}$. Cuaca yang teramati berawan, ratarata suhu $27,4^{\circ} \mathrm{C}$, kelembaban $77 \%$. Hal ini dapat dibuktikan bahwa pada jadwal penerbangan yang berlangsung pada hari tersebut semua pesawat take off ke arah runway 29 yang telah divalidasi dan sesuai dengan data yang terekam oleh Airnav Indonesia cabang Denpasar.

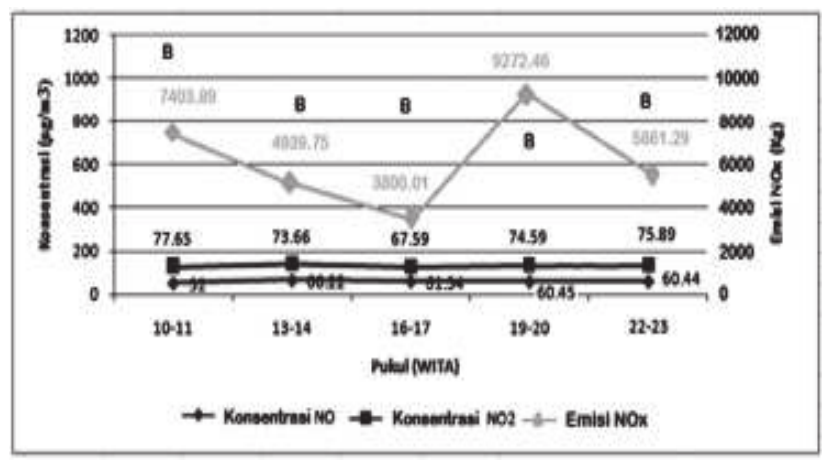

Gambar 3. Emisi Pesawat dan Konsentrasi $\mathrm{NO}, \mathrm{NO}_{2}$ Udara AmbienFase Take Off (titik I) Awal Minggu

Gambar 3 memperlihatkan emisi dan konsentrasi $\mathrm{NO}_{\mathrm{x}}$ udara ambien yang terukur pada titik I. Pagi hari pukul 10.00 - 11.00 WITA 
konsentrasi NO dimulai dengan yang terendah, namun konsentrasi $\mathrm{NO}_{2}$ berada di angka yang tertinggi. Hal ini dapat terjadi karena kondisi cuaca yang teramati berawan dimana penyinaran matahari mencapai $100 \%$ yang mengurai $\mathrm{NO}_{3}$ menjadi $\mathrm{NO}_{2}$ yang sebelumnya juga mengubah $\mathrm{NO}_{3}$ menjadi $\mathrm{NO}$. Perlu diperhatikan bahwa konsentrasi NO selalu berada dalam kondisi rendah pada jam berikutnya menjelang sore hari dan ini bertolak belakang dengan konsentrasi $\mathrm{NO}_{2}$. Konsentrasi $\mathrm{NO}_{2}$ selalu lebih tinggi didandingkan dengan konsentrasi NO.

Reaksi ini terjadi dimulai dengan terpecahnya molekul $\mathrm{NO}_{2}$ menjadi $\mathrm{NO}$ dan $\mathrm{O}$ oleh sinar matahari dengan panjang gelombang tertentu yang menyebabkan jumlah molekul $\mathrm{NO}_{2}$ akan berkurang yang menyebabkan terjadi pertambahan jumlah molekul NO (Oembasta, 2012). Molekul O yang sudah terlepas tersebut akan bereaksi dengan udara $\left(\mathrm{O}_{2}\right)$ yang memicu bertambanya molekul ozon $\left(\mathrm{O}_{3}\right)$. Seiring dengan peningkatan molekul NO yang diikuti peningkatan $\mathrm{O}_{3}$, maka molekul ini akan bereaksi yang menimbulkan peningkatan $\mathrm{NO}_{2}$ dengan demikin $\mathrm{NO}$ akan semakin berkurang pula. Namun dikarenakan sinar matahari yang stabil maka $\mathrm{NO}_{2}$ juga akan berfotodisosiasi dan proses ini akan berulang kembali. Berikut adalah reaksi kimia yang terjadi dari proses ini.

$$
\begin{aligned}
& \mathrm{NO}_{2}+h \mu \rightarrow \mathrm{NO}+\mathrm{O} \\
& \mathrm{O}+\mathrm{O}_{2} \rightarrow \mathrm{O}_{3} \\
& \mathrm{NO}+\mathrm{O}_{3} \rightarrow \mathrm{NO}_{2}+\mathrm{O}_{2}
\end{aligned}
$$

Reaksi tersebut akan terus berulang sampai tidak ada cahaya matahari yang memasok photon bagi $\mathrm{NO}_{2}$ untuk diurai kembali. Hal ini dapat dilihat bahwa berdasarkan hasil pengukuran konsentrasi $\mathrm{NO}_{2}$ setelah pukul 18.00 WITA kembali mengalami peningkatan. Proses ini terjadi ketika matahari terbenam atau jarak matahari dengan lokasi pengukuran sudah sangat jauh. Ketika jarak matahari jauh, maka gelombang cahaya yang sampai ke bumi adalah gelombang cahaya dengan panjang gelombang terpanjang. Semakin besar panjang gelombang, maka energi photon yang dihasilkan sangat kecil, oleh karena itu dengan energi photon yang sangat kecil maka tidak akan mampu mengurai $\mathrm{NO}_{2}$ sehingga menjelang malam konsentrasi $\mathrm{NO}_{2}$ akan meningkat yang diikuti dengan penurunan NO.

Berbeda dengan parameter $\mathrm{NO}$ dan $\mathrm{NO}_{2}$, tingkat signifikan uji $\mathrm{F}$ titik I untuk parameter $\mathrm{CO}$ dalam tiga tren hari penerbangan memperlihatkan bahwa emisi CO dari ketiga fase LTO tidak signifikan terhadap konsentrasi $\mathrm{CO}$ yang terukur yang ditandai dari nilai signifikan yang lebih besar dari taraf signifikan yang ditetapkan yaitu 0,05 . Hal ini juga diikuti dari tingkat sifnifikan uji t koefisien $b_{1}$ untuk parameter $\mathrm{CO}$ yang lebih besar dari taraf signifikan yang ditetapkan. Hal ini menjadi sebuah pertanyaan tersendiri kenapa tidak ditemukannya pengaruh fase tersebut terhadap konsentrasi CO. Tidak adanya pengaruh fase take off terhadap konsentrasi $\mathrm{CO}$ terukur disebabkan oleh beberapa hal yang harus dianalisis lebih jauh untuk menjawab fenomena ini.

Berdasarkan hasil perhitungan emisi $\mathrm{NO}_{\mathrm{x}}$ dan $\mathrm{CO}$ fase take off ini, terlihat bahwa emisi CO sangat jauh lebih kecil dibandingkan dengan emisi $\mathrm{NO}_{x}$. Total emisi CO di fase ini dalam tiga hari perhitungan hanya $680,8 \mathrm{~kg}$ dengan rata-rata 226,93 $\mathrm{kg}$ tiap harinya. Emisi $\mathrm{CO}$ yang dihasilkan pada fase take off sangat kecil, karena pada fase take off pembakaran yang terjadi tergolong pembakaran sempurna. Pembakaran sempurna akan berimbas pada emisi gas CO yang sangat kecil, seperti halnya pada kendaraan bermotor. Emisi secara langsung akan berpengaruh pada kualitas udara ambien di sekitarnya.

Kecepatan lontaran gas buang pada saat pesawat take off seperti pada Gambar 2 mencapai $161 \mathrm{~km} /$ jam. Emisi tersebut sudah terbuang jauh ke arah belakang pesawat udara. Kecepatan angin $6 \mathrm{~m} / \mathrm{s}$ bertiup searah dengan arah lontaran emisi gas $\mathrm{CO}$ ke arah runway 09 sehingga tidak ditemukannya pengaruh emisi CO take off terhadap CO udara ambien.Gambar 4 memperlihatkan emisi $\mathrm{CO}$ fase take off dan konsentrasi hasil pengukuran $\mathrm{CO}$ udara ambient

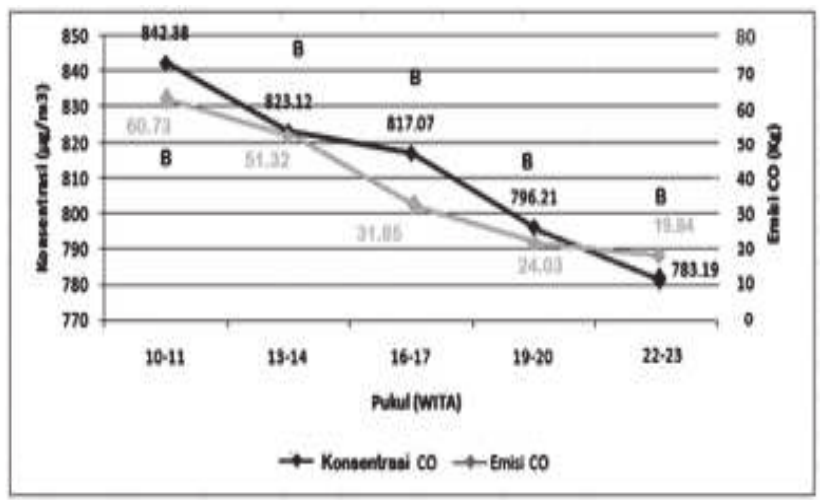

Gambar 4. Emisi Pesawat dan Konsentrasi CO Udara AmbienFase Take Off (titik I) Awal Minggu

Berdasarkan data dari Stasiun BMKG Kelas I Ngurah Rai pengamatan pada hari tersebutarah angin bertiup menuju ke Barat, keadaan berawan, suhu rata-rata $27,4^{\circ} \mathrm{C}$, rata-rata kelembaban $77 \%$ dankecepatan angin rata-rata $6 \mathrm{~m} / \mathrm{s}$. Menurut Soedono (2001), kecepatanangin di daerah perkotaan akan cenderung menurun darikecepatan yang sebenarnya, hal ini terjadi akibat besarnyagesekan yang timbul pada aliran udara, disebabkanoleh banyaknya gedung-gedung bertingkat. Melihat pernyataan ini, kondisi runway bandara yang searah dengan arah pergerakan angin dan terbuka, maka kecepatan angin tidak akan mengalami perlambatan. Mengingat massa jenis $\mathrm{CO}$ yang lebih kecil dari udara, maka akan sangat mudah terbawa oleh tiupan angin yang mengarah ke Barat atau arah runway 09. Kondisi cuaca siang hari, yang diikuti dengan 
pergerakan angin akan menyebabkan penurunankonsentrasi gas karbon monoksida udara ambien karenacepat terurai di udara. Hal ini sesuai dengan pernyataanTjasyono (2004) menyatakan bahwa parametermeteorologi primer yang peka terhadap dispersi pencemaradalah angin dan suhu udara, sedangkan parametermeteorologi sekunder adalah curah hujan dan radiasimatahari.

\subsubsection{Fase Taxi In Titik II (Koefisien $b_{2}$ )}

Rata-rata nilai tingkat signifikan uji $\mathrm{F}$ untuk parameter $\mathrm{NO}$ dan $\mathrm{NO}_{2}$ dalam tiga tren hari penerbangan tersebut adalah $0,033<0,05$. Rata-rata tingkat signifikan hasil uji secara parsial (uji t) yang diperoleh dalam tiga hari tersebut untuk parameter $\mathrm{NO}$ dan $\mathrm{NO}_{2}$ adalah 0,041. Rata-rata nilai $r$ yang diperoleh dalam tiga hari tersebut untuk parameter $\mathrm{NO}$ dan $\mathrm{NO}_{2}$ adalah 0,89 yang menyatakan korelasi yang kuat dengan rata-rata kontribusi sebesar 79\% yang menyatakan bahwa emisi gas $\mathrm{NO}_{\mathrm{x}}$ pesawat udara fase taxi in berpengaruh nyata terhadap konsentrasi $\mathrm{NO}_{\mathrm{x}}$ udara ambien yang terukur.Hasil perhitungan emisi gas $\mathrm{NO}_{\mathrm{x}}$ fase taxi in memperlihatkan bahwa fase taxi in adalah fase yang menghasilkan emisi gas $\mathrm{NO}_{\mathrm{x}}$ tertinggi kedua setelah fase take off dan bahkan jauh lebih besar dari fase landing. Thrust yang digunakan pesawat udara pada fase taxi in hanya sebesar 7\% dan jauh lebih kecil dari fase landing yang besarnya mencapai 30\%. Fenomena yang terjadi di sini adalah mengapa thrust fase taxi in yang jauh lebih kecil dari fase landing, justru menghasilkan emisi gas $\mathrm{NO}_{\mathrm{x}}$ yang jauh lebih besar dari fase landing. Fenomena ini terjadi terletak pada waktu (Time-in-Mode) yang digunakana pada setiap fase. Berdasarkan data dari ICAO, fase taxi in memerlukan waktu yang cukup banyak yaitu sebesar 13 menit, sedangkan fase landing hanya memerlukan waktu sebesar 4 menit. Sehingga, semakin lama waktu yang digunakan pada fase tersebut maka emisi yang terjadi juga akan semakin besar.

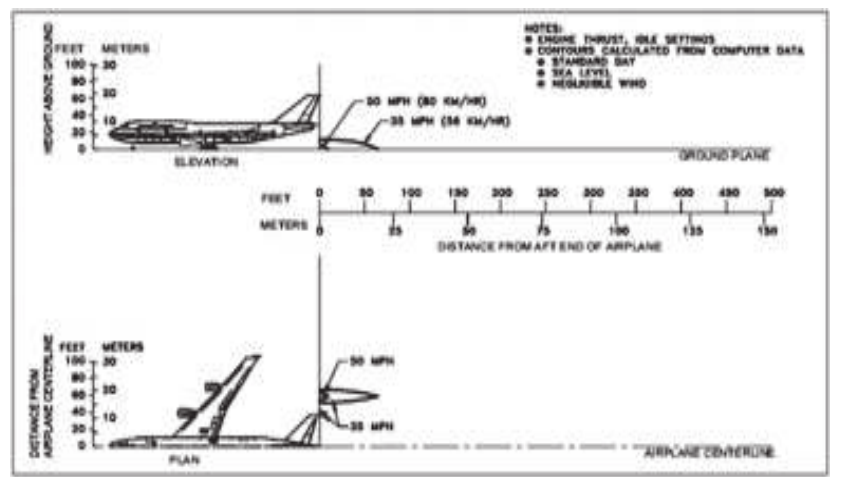

Gambar5.Boeing 747 Exhaust Velocity Fase Taxi In (idle). Sumber: 747 Airport Planning Document (2002)
Gambar 5 memperlihatkan kecepatan lontaran massa udara yang keluar dari mesin pesawat udara fase taxi in. Kecepatan lontaran udara yang mengandung $\mathrm{NO}_{\mathrm{x}}$ lebih kecil dari fase take off yaitu hanya sebesar $56 \mathrm{~km} / \mathrm{jam}$ sehingga tidak akan terbuang jauh dari lokasi titik pengukuran. Selain itu, beberapa faktor berikut juga menjelaskan pengaruh faktor tersebut terhadap konsentrasi $\mathrm{NO}_{\mathrm{x}}$ udara ambien.

Berdasarkan data yang diperoleh dari Stasiun BMKG Kelas I Ngurah Rai, dengan rata-rata keadaan cuaca berawan, suhu $27,9^{\circ} \mathrm{C}$, kelembaban $74 \%$ dan angin bertiup ke arah Barat runway09 dengan kecepatan rata-rata $6 \mathrm{~m} / \mathrm{s}$. Gambar 6 memperlihatkan emisi dan konsentrasi $\mathrm{NO}_{\mathrm{x}}$ udara ambien yang terukur di titik tersebut.

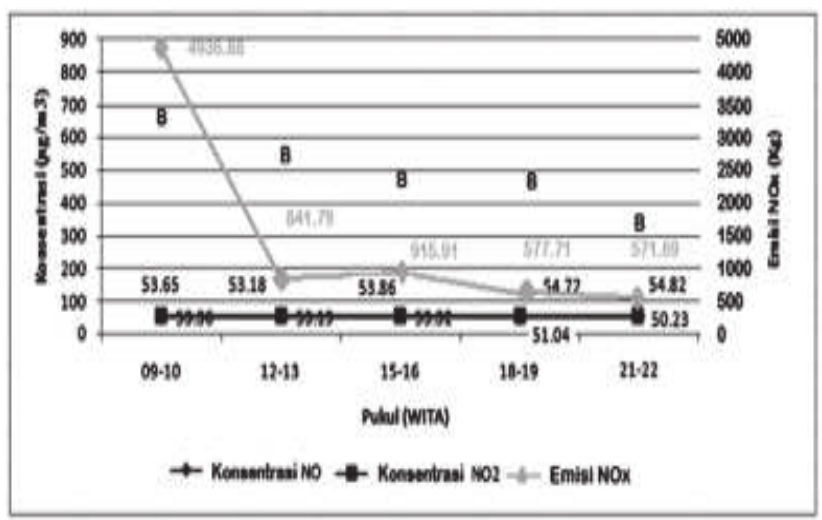

Gambar 6.Emisi Pesawat dan Konsentrasi NO, $\mathrm{NO}_{2}$ Udara AmbienFase Taxi In (Titik II) Akhir Minggu

Grafik yang diperlihatkan untuk titik II ini memiliki sedikit perbedaan dengan grafik titik lainnya. Perbedaan terlihat ketika konsentrasi NO dan $\mathrm{NO}_{2}$ hampir sama namun pola penurunan $\mathrm{NO}$ menjelang sore hari dan peningkatan $\mathrm{NO}_{2}$ sore hari masih sama dengan titik lainnya.

Konsentrasi $\mathrm{NO}$ dan $\mathrm{NO}_{2}$ yang hampir sama di titik ini disebabkan oleh laju reaksi pemecahan $\mathrm{NO}_{2}$ menjadi $\mathrm{NO}$ dan $\mathrm{O}$ yang begitu cepat dan perubahan $\mathrm{NO}$ menjadi $\mathrm{NO}_{2}$ yang cepat pula. Laju reaksi yang begitu cepat ini disebabkan oleh beberapa faktor diantaranya adalah sinar matahari, ozon dan pergerakan udara. Cuaca yang teramati pada saat pengambilan sampel di titik ini didominasi oleh cuaca berawan dan penyinaran sinar matahari ke bumi mencapai 100\% sehingga cahaya matahari yang bertindak sebagai katalisator sangat cepat membantu proses penguraian $\mathrm{NO}_{2}$ menjadi $\mathrm{NO}$ dan O. Pegerakan udara yang cepat akan menimbulkan suhu di permukaan tanah akan sama dengan suhu udara di atasnya. Suhu udara yang tinggi akan menyebabkan kerapatan udara menjadi kecil dan akan sangat cepat berbaur dengan udara di atasnya sehingga proses pembentukan ozon akan semakin cepat yang mengakibatkan reaksi ozon dan NO juga akan cepat. 
Berbeda dengan titik I, titik II untuk parameter $\mathrm{CO}$ rata-rata tingkat signifikan dari uji $\mathrm{F}$ yang diperoleh sebesar 0,034 yang menyatakan semua variabel LTO secara simultan berpengaruh terhadap konsentrasi CO terukur. Namun dari hasil uji t diperoleh hanya fase taxi in saja yang memiliki tingkat signifikan yang lebih kecil dari taraf signifikan yang ditentukan yaitu sebesar $0,036<0,05$ yang menyatakan adanya pengaruh aktivitas taxiin tersebut terhadap hasil pengukuran $\mathrm{CO}$ di titik tersebut. Tingkat kontribusi emisi gas CO mencapai $71 \%$ dan merupakan satu-satunya fase yang berpengaruh terhadap hasil pengukuran kualitas CO udara ambien.

Fase taxi in adalah fase yang menyebabkan emisi gas $\mathrm{CO}$ terbesar diantara dua fase lainnya. Fase ini memerlukan thrust hanya sebesar $7 \%$ sehingga energi yang dibutuhkan juga kecil. Fase ini terhitung setelah pesawat melakukan fase landing dan bergerak secara perlahan hingga ke lokasi aprron(idle). Seperti pada kendaraan bermotor, pada saat mendekati proses idle pembakaran yang terjadi dalam mesin tergolong pembakaran tidak sempurna sehingga emisi gas CO sangat besar.

Berdasarkan Gambar 5, kecepatan lontara gas $\mathrm{CO}$ sebesar $56 \mathrm{~km} / \mathrm{jam}$. Kecepatan lontaran udara fase taxi in lebih kecil dibandingkan fase take off yang besarnya mencapai $161 \mathrm{~km} / \mathrm{jam}$. Kecepatan lontaran udara fase taxi in yang kecil ini menyebabkan gas yang terlontar tidak begitu jauh dari lokasi bandara sehingga masih berpengaruh terhadap kualitas udara ambien yang terukur. Perlu diperhatikan bahwa emisi CO taxi in adalah yang terbesar diantara fase lainnya. Hal ini yang menyebabkan pada titik ini ada korelasi atau kontribusi emisi CO terhadap hasil pengukuran udara ambien.

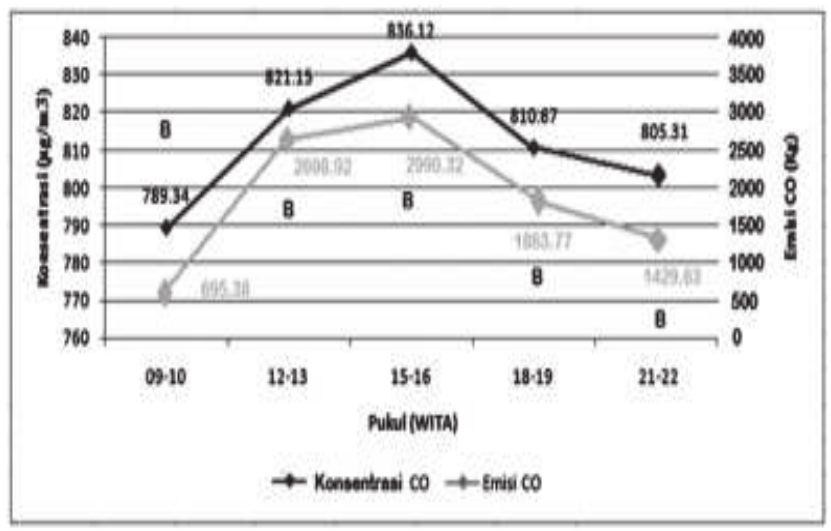

Gambar 7. Emisi Pesawat dan Konsentrasi CO Udara AmbienFase Taxi In (Titik II) Akhir Minggu

Konsentrasi CO di titik ini cenderung stabil dan pada siang hari justru mengalami sedikit peningkatan. Gambar 7 terlihat hal ini terjadi dikarenakan oleh emisi CO yang terjadi pada fase ini adalah yang terbesar di antara fase lainnya. Data yang diperoleh dari Stasiun BMKG Kelas I Ngurah
Rai Bali dengan rata-rata keadaan cuaca berawan, suhu rata-rata $28,1^{\circ} \mathrm{C}$, kelembaban $76 \%$ dan kecepatan angin $6 \mathrm{~m} / \mathrm{s}$ bertiup menuju ke arah Barat runway pesawat. Ketika emisi gas $\mathrm{CO}$ ini terbawa oleh tiupan angin, maka emisi gas CO yang sangat banyak ini mengalami perlambatan karena angin bertiup ke arah Barat dimana pada posisi tersebut sudah terdapat deretan gedung dan merupakan lokasi parkir pesawat dan alat-alat lainnya sehingga jika ada gas $\mathrm{CO}$ yang terbawa angin akan mengalami perlambatan dan akan berkumpul disekitar appron bandara dimana tempat tersebut merupakan titik pengambilan sampel $\mathrm{CO}$.

\subsubsection{Fase Landing Titik III (Koefisien $b_{3}$ )}

Titik III adalah titik pengukuran yang mewakili fase landing di runway 09. Hasil regresi pada hari Senin, Rabu dan Sabtu di titik tersebut memperlihatkan bahwa semua aktivitas fase landing baik untuk parameter $\mathrm{NO}_{\mathrm{x}}$ maupun $\mathrm{CO}$ di titik III tidak berpengaruh terhadap konsentrasi yang terukur. Hal ini terlihat dari hasil uji $\mathrm{F}$ yang memperoleh tingkat signifikan yang lebih besar dari taraf signifikan yang ditentukan. Rata-rata tingkat signifikan yang diperoleh dalam tiga tren hari penerbangan di titik III tersebut sebesar 0,92>0,05. Hal ini terjadi karena emisi yang dihasilkan oleh pesawat pada fase ini sangat kecil dibandingkan dengan emisi di fase take off dan taxi in.Meskipun thrust yang digunakan pada fase ini sebesar 30\% namun waktu yang diperlukan hanya sebesar 4 menit maka emisi yang terjadi juga akan kecil.

Pada saat pesawat memasuki fase landing, emisi cenderung dilontarkan ke arah belakang sehingga emisi sudah jauh terbuang ke arah Barat runway 09. Besaran thrust yang digunakan pada saat pesawat berada pada fase landing adalah $30 \%$, ini berarti bahwa emisi gas buang yang dilontarkan dari hasil pembakaran sudah jauh terbuang dengan kecepatan yang lebih besar dari fase taxi in. Namun hasil pengambilan sampel pada titik III ini secara umum memperlihatkan hasil yang tidak berbeda dengan titik lainnya.

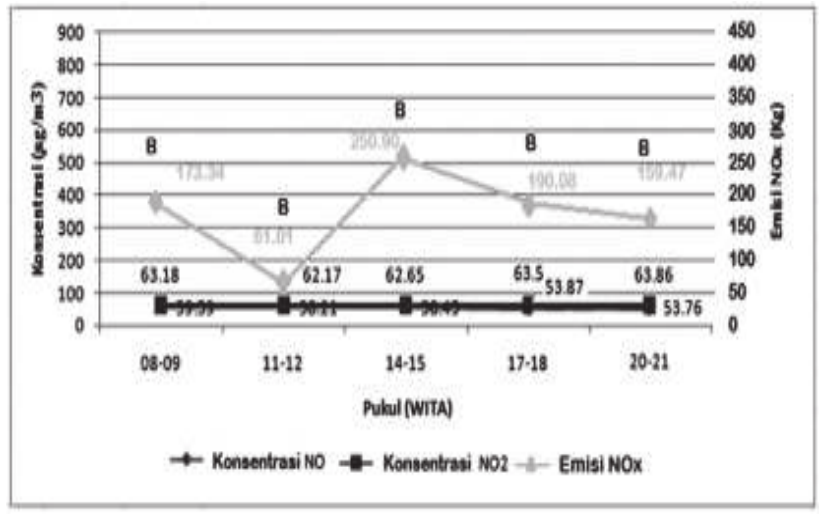

Gambar 8. Emisi Pesawat dan Konsentrasi NO, $\mathrm{NO}_{2}$ Udara Ambien Fase Landing (Titik III) Akhir Minggu 
Kecepatan angin rata-rata $6 \mathrm{~m} / \mathrm{s}$, cuaca berawan, suhu $27,9^{\circ} \mathrm{C}$ dan kelembaban $74 \%$. Grafik titik III ini memiliki pola yang mirip dengan titik I, dimana konsentrasi NO selalu lebih rendah dibandingkan $\mathrm{NO}_{2}$. Konsentrasi $\mathrm{NO}$ dimulai dengan konsentrasi yang rendah dan meningkat pada siang hari kemudian menurun kembali pada sore hari. Penurunan $\mathrm{NO}$ disebabkan meningkatnya $\mathrm{NO}_{2}$ yang tidak bisa diurai karena tidak adanya sinar matahari atau tidak adanya sinar matahari dengan panjang gelombang yang cukup untuk mempercepat reaksi kimia tersebut. Secara umum, pola grafik untuk titik III ini memiliki kemiripan dengan titik I sebelumnya.

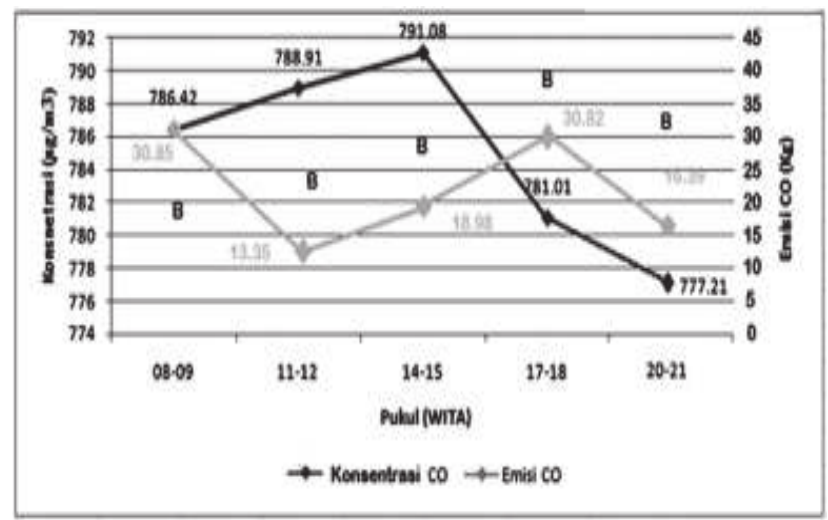

Gambar 9. Emisi Pesawat dan Konsentrasi CO Udara AmbienFase Landing (Titik III) Akhir Minggu

Konsentrasi CO di titik III ini selalu lebih rendah dari titik lainnya, karena emisi di titik ini juga sangat kecil dan berdasarkan hasil regresi tidak ada pengaruh emisi fase landing terhadap hasil pengukuran $\mathrm{CO}$.

\section{SIMPULAN DAN SARAN}

\subsection{Simpulan}

a. Rata-rata emisi aktivitas LTO (take off, taxi in dan landing) pesawat udara per tren hari penerbangan (awal, pertengahan dan akhir minggu) masing-masing untuk gas $\mathrm{NO}_{\mathrm{x}}$ dan $\mathrm{CO}$ adalah sebesar 43,145 ton dan 17,922 ton/hari.

b. Aktivitas LTO pesawat udara di Bandar Udara Internasional I Gusti Ngurah Rai Bali memiliki pengaruh yang nyata terhadap konsentrasi $\mathrm{NO}_{\mathrm{x}}$ dan CO udara ambien yang ditandai dari hasil uji $\mathrm{F}$ secara simultan dengan rata-rata tingkat signifikan 0,033<0,05 dan nilai $r$ berkisar antara 0,77 - 0,97 dengan rata-rata konstribusi sebesar $79,1 \%$.

c. Hasil pengukuran kualitas udara ambien pada ketiga titik pengukuran secara umum masih berada di bawah baku mutu berdasarkan PP Nomor 41 tahun 1999.

\subsection{Saran}

a. Diharapkan adanya penelitian lebih lanjut untuk menghitung beban emisi pesawat udara selain gas $\mathrm{NO}_{\mathrm{x}}$ dan $\mathrm{CO}$.

b. Perlu adanya penelitian lebih lanjut untuk mengukur kualitas udara ambien secara paralel pada ketiga titik secara bersamaan.

\section{DAFTAR PUSTAKA}

BMKG, 2014. Pola Arah Angin Bulan Mei 2014. Bali, Indonesia: Stasiun Meteorologi Kelas I Ngurah Rai.

BMKG, 2014. Suhu dan Kelembaban tanggal 5, 7 dan $10 \mathrm{Mei}$ 2014. Bali, Indonesia:Stasiun Meteorologi Kelas I Ngurah Rai.

Boeing Company. 2002. 747 Airport Planning Document: Boeing 747 Exhaust Velocity Take Off. Diakses dari http://www.boeing.com/ tanggal 06 April 2014.

Boeing Company. 2006. Airport Planning Document: Boeing 747 Exhaust Velocity Taxi In (Idle). Diakses dari http://www.boeing.com/tanggal 18 Juli 2014.

EMEP/EEA. 2009. Emission Inventory Guidebook 2009: Annex 16 Volume II AircraftEngine Emission.

Fardiaz, Srikandi. 1992. Polusi Udara dan Air. Yogyakarta, Indonesia: Kanisius p.89-142.

Federal Aviation Administration Office of Environment and Energy, 2005. Aviation and Emissions - A Primer.

International Civil Aviation Organization, 2010. Environment Report 2010.

Mukono, H.J. 2006. Prinsip Dasar Kesehatan Lingkungan. Surabaya, Indonesia: Edisi Kedua, Airlangga Press.

Muryanto, D., Surahma, A.M., Dyah S. 2009. Penurunan Kadar Emisi Gas Buang Karbonmonoksida (CO) dengan Penambahan Arang Aktif pada Kendaraan Bermotor di Yogyakarta. Jurnal KESMAS, 3 (3): 162-232

Ombasta, O. 2012. Pengaruh Siklus Landing Take Off Pesawat Udara di Bandar Udara terhadap Fluktuasi Kadar $\mathrm{NO}_{x}$ pada Udara Ambien. Depok, Indoneisa: Universitas Indonesia.

Peraturan Pemerintah, Nomor 41 Tahun 1999 tentang Pengendalian Pencemaran Udara.

PT. Angkasa Pura I, 2012. Laporan Pengelolaan dan Pemantauan Lingkungan di Bandar Udara Internasinal I Gusti Ngurah Rai Bali Semester 2 Tahun 2012. Bali, Indonesia: Angkasa Pura.

Siswanto. 1991. Toksikologi Industri. JawaTimur Surabaya, Indonesia: Balai Hiperkes Kanwil Depnaker.

Tjasyono HK, Noyong. 2004. Klimatologi. Bandung, Indonesia: Penerbit ITB. 